\title{
David Delfín
}

Sala Canal de Isabel II

Del 20 febrero al 10 mayo 2020

Ya se está convirtiendo en una tradición elogiable que cada cierto tiempo la Sala Canal de Isabel II de Madrid ofrezca una exposición temporal sobre moda, de esas que consiguen llamar la atención hasta de los más jóvenes, y que sea de acceso gratuito, algo que no ocurre con otras muestras del mismo ámbito, como las que presentan el Victoria \& Albert Museum de Londres, el Metropolitan Museum de Nueva York o, un caso más cercano, el Museo Nacional Thyssen-Bornemisza. Si bien, no es la única institución madrileña que acerca este tipo de exhibiciones a todos los púbicos, pues también debemos destacar la labor de la Real Academia de Bellas Artes de San Fernando o el propio Museo del Traje.

En esta ocasión, el equipo de la Comunidad de Madrid, capitaneado por el comisario de la muestra, Raúl Marina de Miguel, ha decidido homenajear al aclamado diseñador David Delfín (1970-2017) en el año que alcanzaría el decalustro. Una exposición aparentemente sencilla, pues su trayectoria profesional en el mundo de la moda fue desgraciadamente corta y el periodo abarcado era muy limitado. La complejidad residía entonces en adentrarse en el universo del artista malagueño y para ello contaban con un sinfín de fuentes orales dispuestas a relatar su historia, como se pudo ver en la inauguración de la exposición y en las entrevistas surgidas tras el inicio de la muestra, además de numerosos artículos en prensa y algunos científicos. Sin embargo, el uso hecho de esta información fue superficial, al menos aparentemente y tras la lectura del catálogo, pues ciertamente el espectador no consigue adentrarse en el espíritu de las colecciones del enfant terrible de la moda española.

Este homenaje, que podríamos definir como antológico, monográfico y conmemorativo, carecía de una densa y trabajada investigación previa, fundamental para cualquier exposición histórica-artística. Cierto es que en ocasiones el espectador no alcanza a comprender todo el contenido que conforma el discurso por la complejidad de la temática, o a veces ni siquiera se busca porque las intenciones son otras, como puede ser el simple goce estético. Estas justificacio- nes valdrían para aquellas exposiciones que necesiten de conocimientos previos o, por ejemplo, para una exhibición de alta costura, donde la riqueza de los materiales, la precisión de las puntadas y la belleza del diseño es más que suficiente para absorber al espectador. Pero al tratarse de prendas prêt-à-porter no bastaba con colocarlas aisladas cronológicamente, y más si hablamos de un artista multidisciplinar y con tantos referentes como David Delfín.

Los textos que acompañaban cada una de las salas eran reducidos y no demasiados explicativos. No se trataba de saturar al espectador con paneles interminables, sino de hacer visible lo que David Delfín identificaba como la base de su trabajo, las «ideas y emociones». Las alusiones a personajes tan influyentes en la trayectoria del malagueño como Louise Bourgeois (1911-2010), Joseph Beuys (1921-1986) o Luis Buñuel (1900-1983) quedaron en eso, meras citas. Al tratarse de artistas no demasiado conocidos por el gran público difícilmente podía comprobar que lo expuesto en las informaciones de acceso era cierto. Lo idóneo hubiera sido plantear un diálogo entre los diseños de Delfín y obras de estos artistas, como suelen hacer en el Museo Nacional Thyssen-Bornemisza. Incluso si hablamos de un problema de presupuesto, con que hubieran estado presentes a través de fotografías en las paredes, las cartelas o las hojas de sala, ya hubiera sido útil para identificar las «ideas» que motivaron la realización de estos trajes.

En cuanto a las «emociones", hubiera sido conveniente proporcionar una puesta en conocimiento de su biografía, pues resulta fundamental para la compresión de algunas de sus propuestas. Lo podemos ver en la importancia de la figura materna en el diseño elegido de la colección Intimidad (otoño/invierno 2008/2009), que evidentemente guarda una fuerte relación con la obra de Bourgeois [1]; el choque que supuso la muerte de su padre y cómo volcó su dolor en Diastema (primavera/verano 2009), de la que no había ni siquiera representación en la exposición a pesar de ser un punto de inflexión de su carrera y el paso previo a Nueva York; o también el fallecimiento de su perrita Alicia, que enlutó la pasare- 


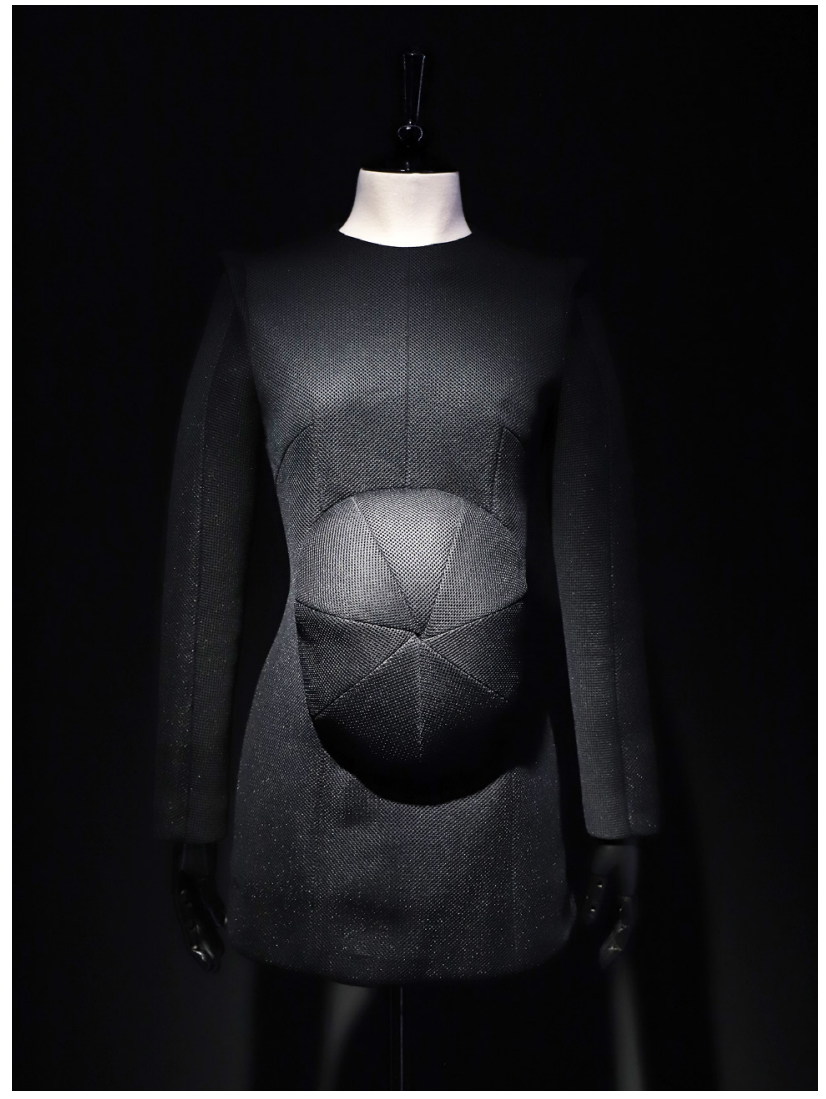

1. Intimidad (otoño/invierno 2008/2009). (C) Cristina Valenciano Rey

la de blanco en Missing (otoño/invierno 2013/2014), al estilo de las reinas europeas medievales [2]. Aspectos que no han sido tomados en cuenta o que no se han sabido reflejar.

A favor de su comisario hay que decir que no era precisamente una tarea fácil. Cada uno de estos modelos aglutinaba una historia detrás que en su momento fue contada con muchos looks (y aquí solo se exponía uno, dos o tres, como mucho, de una misma colección) que desfilaron acompañados de una comunicativa escenografía, una música evocadora y antecedidos por una explicativa nota de prensa. En contraposición, en esta exposición todas las piezas aparecían descontextualizadas, una tras otra delante de un fondo negro, por lo que se quedaron muchas cosas en el tintero, desde las referencias a René Magritte (1898-1967) en su primera colección, Cour des miracles (primavera/verano 2003), con las famosas capuchas [3], hasta el abrigo a base de bufandas con el escudo de España de su último desfile Mentiras (otoño/

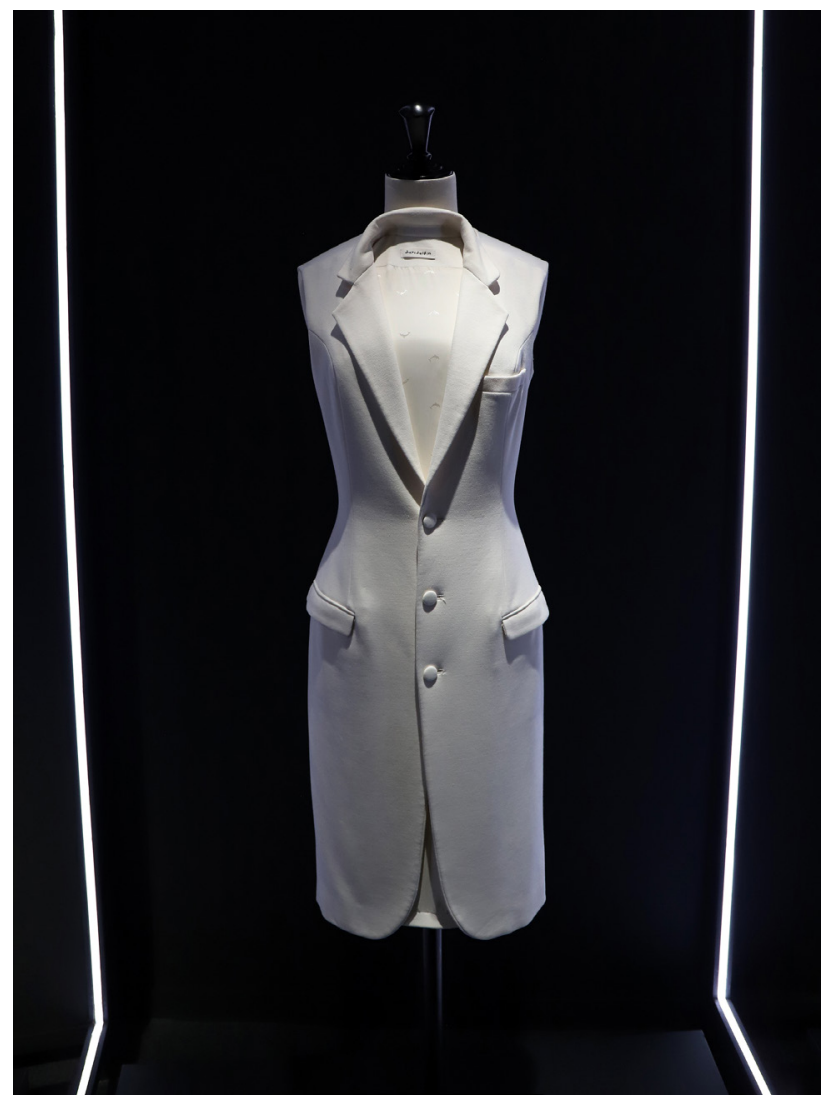

2. Missing (otoño/invierno 2013/2014). C Cristina Valenciano Rey

invierno 2016/2017), en el que propuso trasladar el fervor por el fútbol a la moda española [4]. En cada uno de los maniquís había un ejemplo, a veces no demasiado bien elegido, de la trayectoria del rondeño, pero que sin la necesaria explicación explícita o visual de su diseño quedaba totalmente deslucido. En efecto, podemos hablar de una falta de diálogo entre las prendas mostradas y las motivaciones que lo llevaron a ejecutar estos trajes de un determinado modo.

Algo tan sencillo y efectivo como las cartelas hubieran aliviado la falta de información, pero lamentablemente estas no incluían ni las medidas ni lo que, en este caso, era más importante aún, los materiales y la técnica, a excepción del primer acto. En esta planta se podían leer algunos detalles matéricos como, por ejemplo, de su exposición Sans Titre (1999), de la que se recoge una «Camiseta y chaqueta militar de segunda mano", pero no se habla de la pintura sobre estas prendas, consecuencia de la búsqueda de nue- 


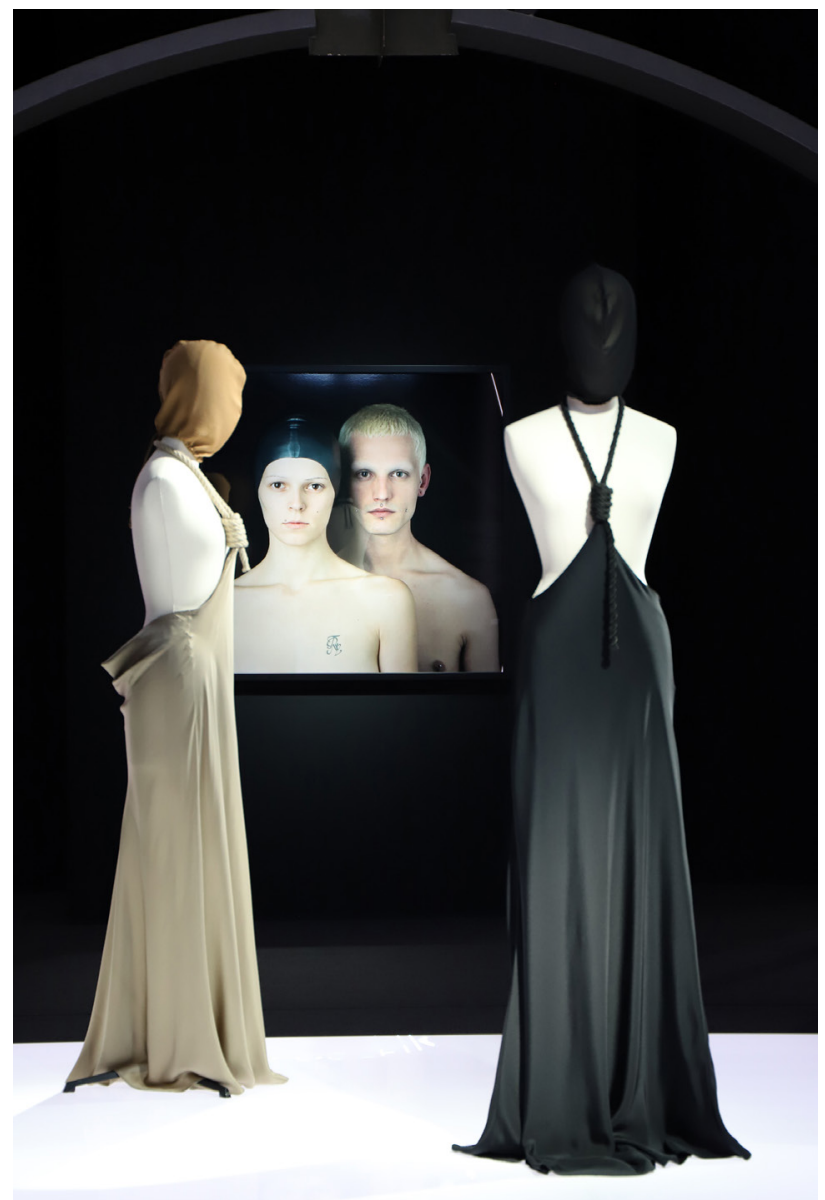

3. Cour des miracles (primavera/verano 2003). @ C Cristina Valenciano Rey

vos soportes, que en este caso comportaban una memoria de aquellos que las llevaron puestas (nombres, manchas, zurcidos, etc.); de su caligrafía torpe, realizada con la mano izquierda, como la de un niño primerizo, en una evolución similar a la de su paisano Pablo Picasso (1881-1973), que empezó pintando realista y acabó haciéndolo como un niño; o las cruces de fieltro, influencia de Beuys [5].

El fieltro merece un capítulo aparte pues, aunque no es muy apropiado para la indumentaria de lujo, David Delfín lo utilizó en numerosas ocasiones, además de la que acabamos de señalar. En la exposición había un traje de Ladies and Gentlemans (otoño/invierno 2005/2006) ingeniosamente colocado en percha como el Felt Suit (1970) de Joseph Beuys (núm. de inv. T07441. Tate Gallery, Londres) [6]. El mismo material fue empleado en Demenagement (otoño/in-

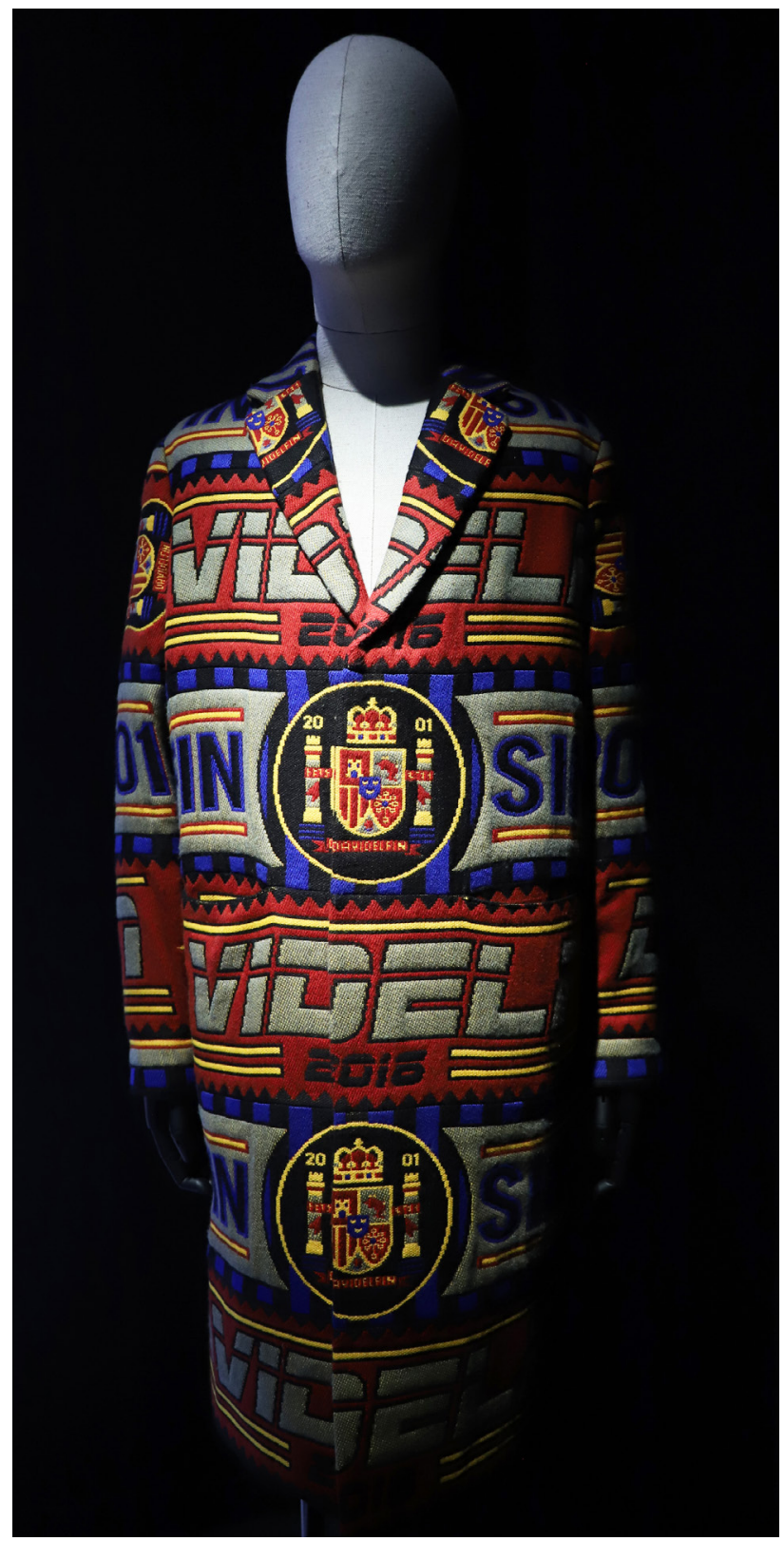

4. Mentiras (otoño/invierno 2016/2017). (C) Cristina Valenciano Rey

vierno 2007/2008), del francés «mudanza», para recrear las mantas de embalaje utilizadas cuando se cambiaba de hogar, un desfile remembranza donde el malagueño rescataba todas las piezas del desván para que no cayeran en el olvido, como simulaba la obra en madera AP 200605 Headdress, de Pablo Reinoso, elegida para la exposición madrileña y que también desfiló en 2006 [7]. En Diogenes Syntrome 


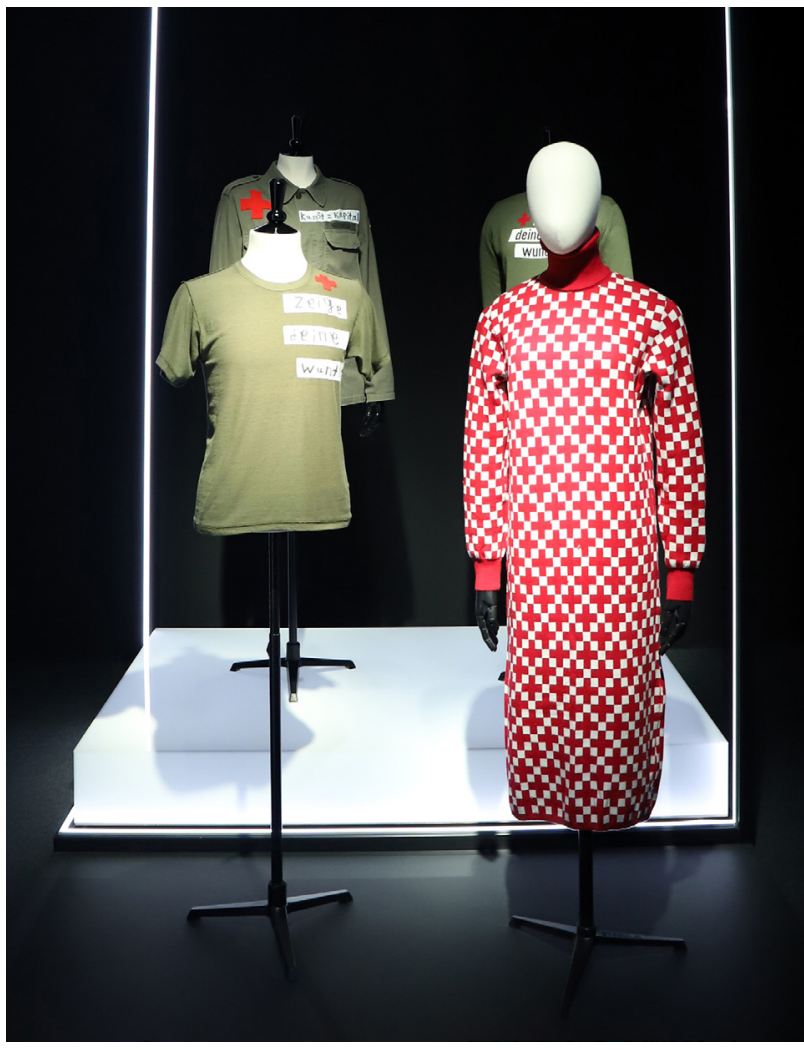

5. Sans Titre (1999). Pater (otoño/invierno 2006/2007). (C Cristina Valenciano Rey

(otoño/invierno 2011/2012) volvió a usar el fieltro, como se puede comprobar en los diseños rescatados para la muestra, donde solapó diferentes prendas de ropa como hiciera Michelangelo Pistoletto en sus cerros de ropa, que simbolizaban la acumulación de emociones. De esto deducimos que el espectador que visitaba la exposición se enfrentaba a materiales de no demasiada calidad, lo cual podría hacerle dudar del buen hacer del diseñador pero, como hemos podido comprobar, esto tenía un porqué, y el discurso expositivo debía haberse adelantado y responder esta incógnita.

A nivel técnico, en la cartela de la prenda seleccionada de la colección Pater (otoño/invierno 2006/2007) se podía leer: «Vestido de punto mecánico» [5]. Tras esta pequeña referencia no se aportaban más características textiles de resto de trajes expuestos, sin contar con las definiciones de «Suéter corbata», "Abrigo negro» o «Abrigo crudo», explicaciones que no proporcionaban informaciones relativas a la confección, el tejido o su decoración. Y esto ocurre solo

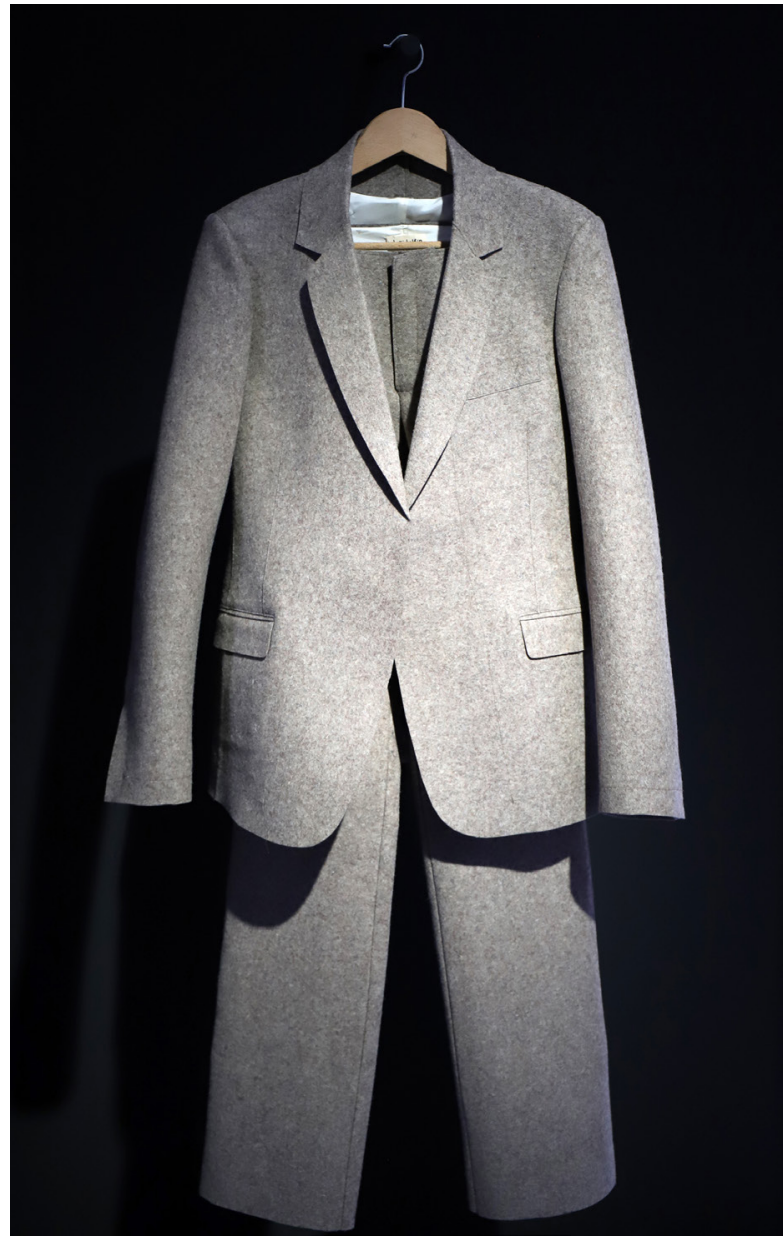

6. Ladies and Gentlemans (otoño/invierno 2005/2006). C Cristina Valenciano Rey

en la primera parte, porque en el resto de los actos de la muestra definitivamente se deja de hacer alusión a este importante apartado en el inventario de piezas artísticas. La tejeduría o el ornato de esta indumentaria no pueden ser tomados como un asunto baladí, ya que nos aportan datos relevantes para su catalogación. Que el Vestido Magritte, de la colección Cour des miracles, sea un raso bordado, o que la camisa de Inferno (otoño/invierno 2015) sea un acrílico sobre tafetán pintado por Santiago Ydáñez (Puente de Génave, Jaén, 1969), revelan que estamos ante piezas únicas, no reproducidas en serie, por ello su valor artístico es mayor [8].

Como hemos relatado, la exposición es un listado de trajes necesitados de narración, desprovistos de las influencias de David Delfín y de la explicación que dé sentido al uso 


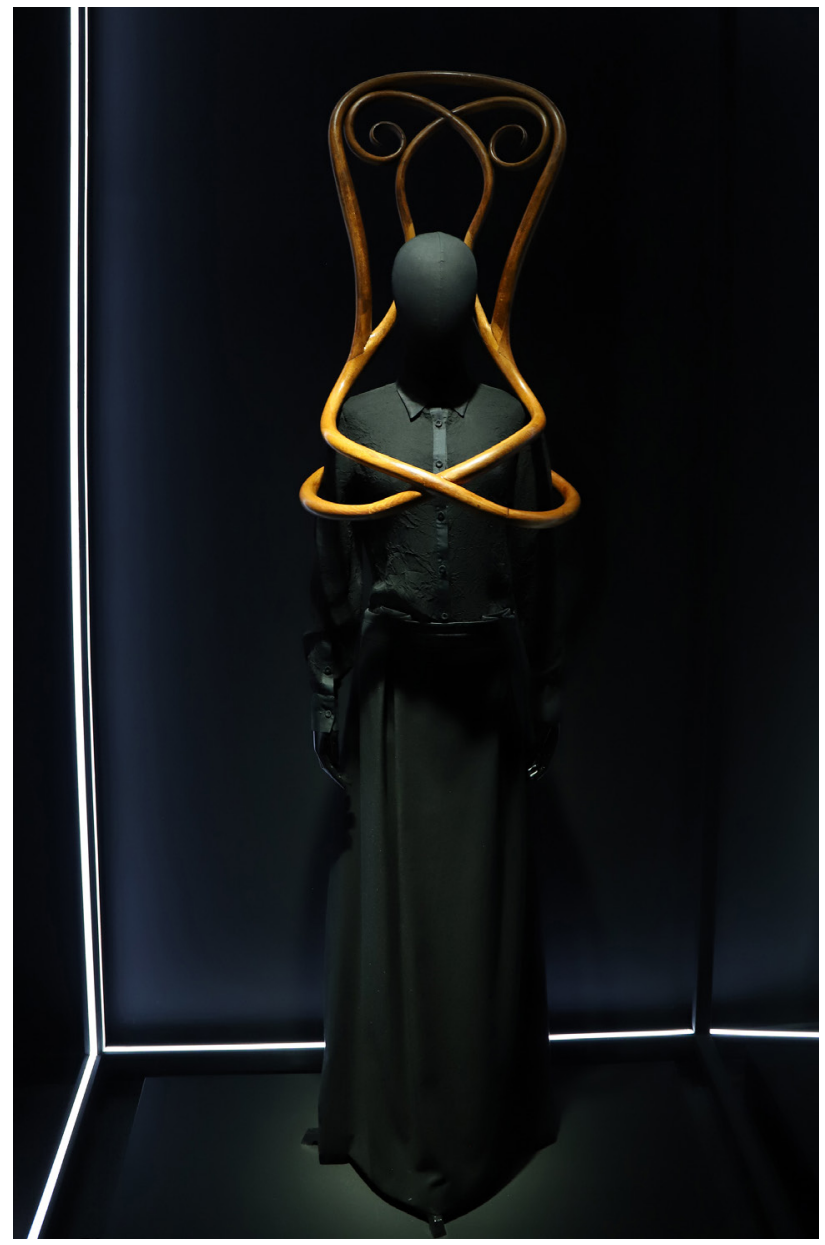

7. AP 200605 Headdress (2006), Pablo Reinoso-Demenagement (otoño/ invierno 2007/2008). (C) Cristina Valenciano Rey

de esos materiales y su forma. El vestido elegido para representar la colección Katharsis (primavera/verano 2012), por ejemplo, fue una explosión de belleza y color en su momento, pero ahora tiene muchos hilos sueltos, en sentido literal. ¿Por qué estas piezas no fueron remalladas, se preguntará el espectador? Porque el citado desfile llegó en un momento económico precario para el diseñador, por eso se planteó la posibilidad de crear una colección con las muestras textiles que le proporcionaron los proveedores, hasta conseguir ese efecto pantone de Le Corbusier (1887-1965). El artista malagueño dibujó esta tabla de colores en varias ocasiones, personas cercanas a él tienen esta obra, también se mostró en su exposición Interiores (del 12 de septiembre al 11 de octubre de 2013, La Fresh Gallery, Madrid), incluso fue el

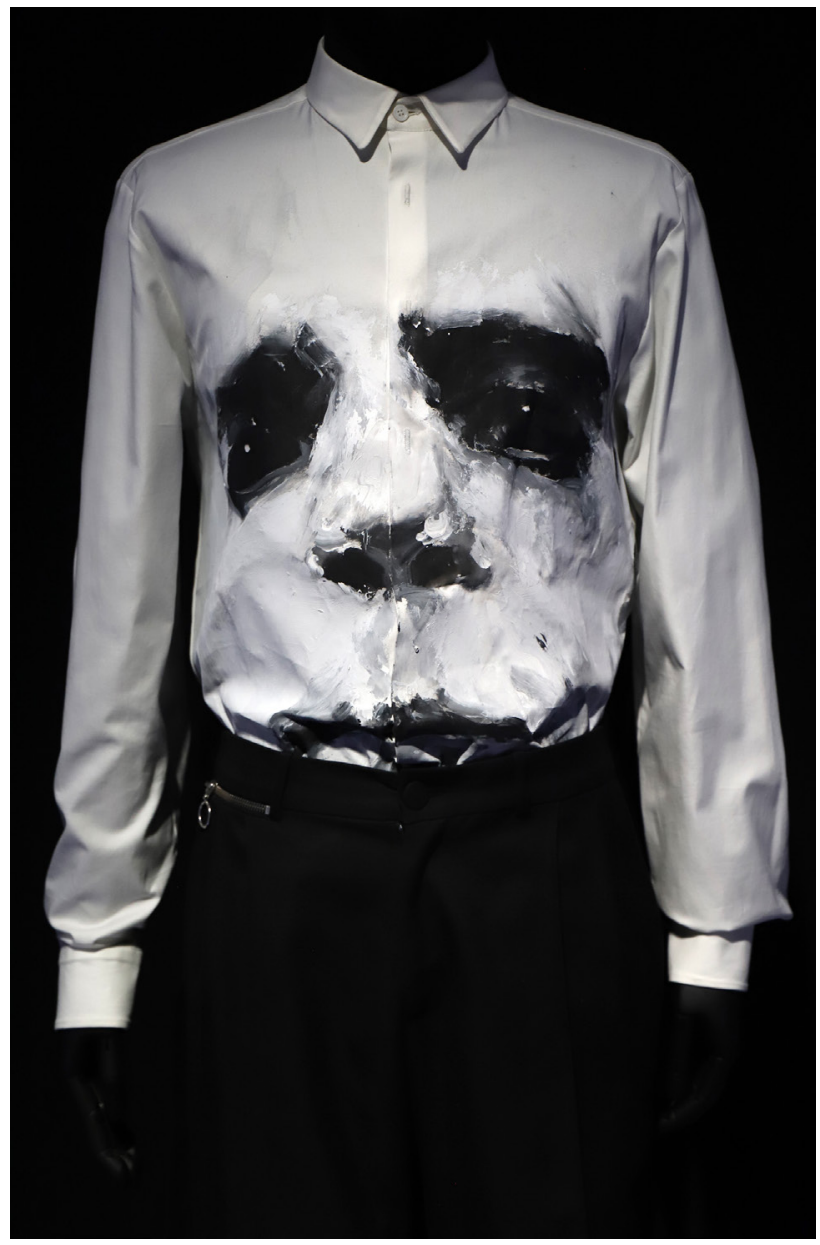

8. S. T. (2014), Santiago Ydáñez-Inferno (otoño/invierno 2015/2016). @ Cristina Valenciano Rey

estampado de uno de sus edredones en su colección para hogar y, sin embargo, el público se queda con la imagen de un vestido aislado hecho de retales.

La solución a esta falta de claridad discursiva se podía haber solucionado con el uso intercalado de las obras pláticas y audiovisuales de David Delfín, de las que ya hemos adelantado algo, con los trajes. Parte de esta colección estaba en la penúltima planta de la exposición, por lo que, si en vez de haberla aislado en un último piso, hubiera acompañado cada uno de los looks expuestos, el recorrido hubiera sido mucho más dinámico y, sobre todo, comunicativo. ¿De qué sirve poner los bocetos de la colección Will (otoño/ invierno 2012/2013) alejados del «vestido real», como diría Roland Barthes (1915-1980) [9]? Si no mostramos el paso 


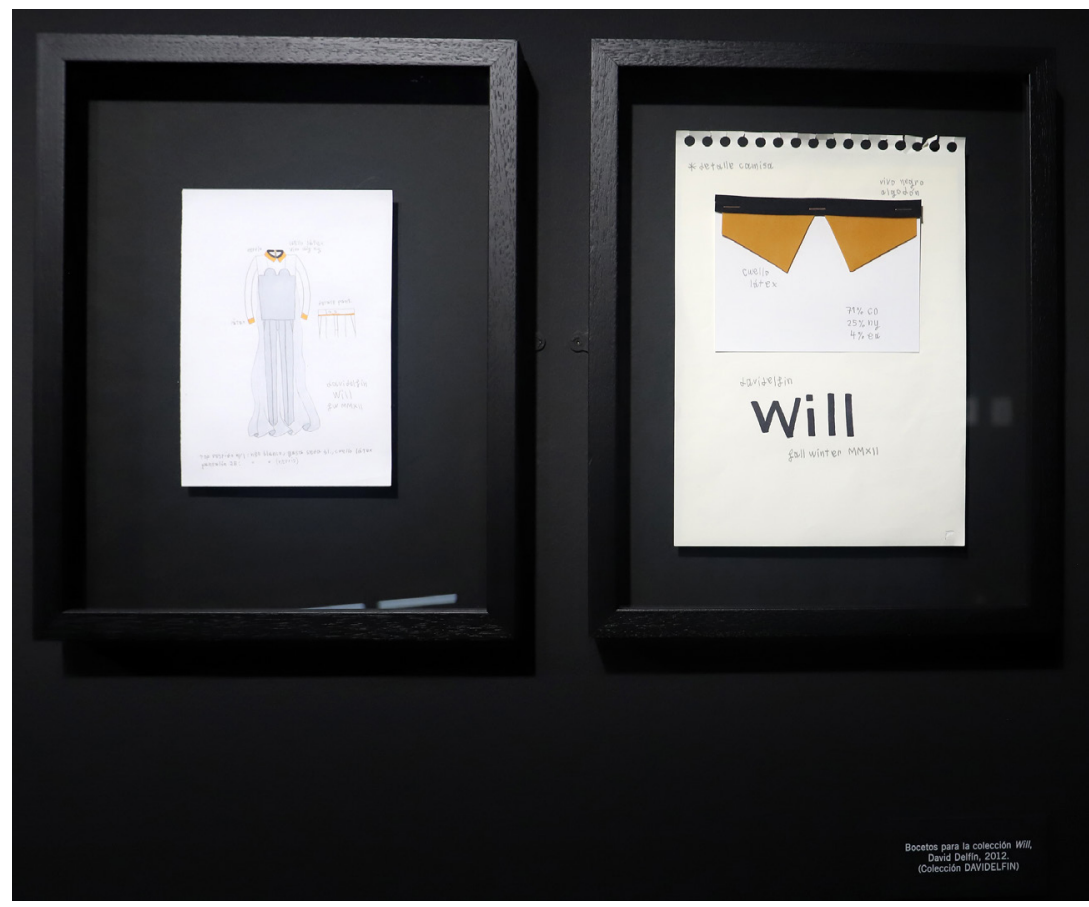

9. Bocetos para

la colección Will

(otoño/invierno

2012/2013).

(C) Cristina

Valenciano Rey

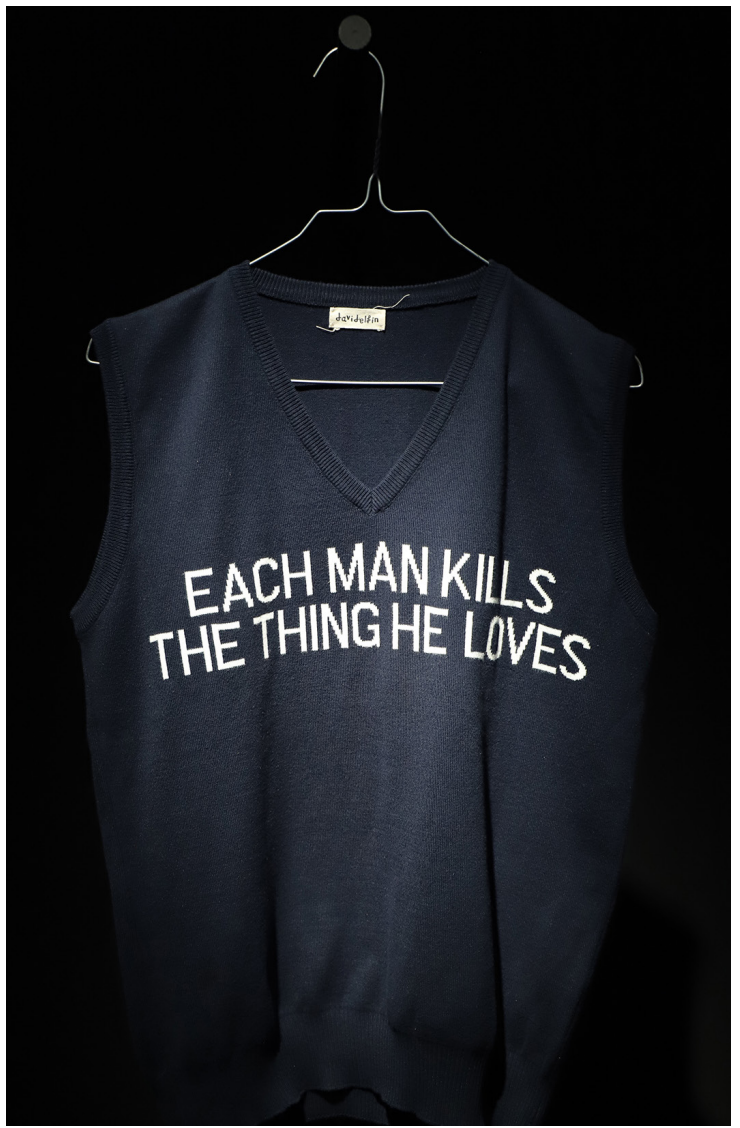

10. Dual (primavera/

verano 2008). (C)

Cristina Valenciano Rey de la idea a la pieza final el público difícilmente puede plantearse un recorrido en su cabeza desde la recepción de influencias hasta la ejecución de la prenda y la presentación al mundo a través del desfile.

David Delfín culmina en la Sala Canal de Isabel II con una proyección en la bóveda que simula un cielo y, de fondo musical, la canción Como yo te amo, de Rocío Jurado (19442006), cantada por Bimba Bosé (1975-2017). Esta versión fue la banda sonora de Dual (primavera/verano 2008), por lo que hubiera tenido más sentido que sonara cerca del chaleco expuesto con el mensaje «Each man kills the thing he loves» («Cada hombre mata lo que ama»), por cierto, en una percha de alambre que dejaba bastante que desear, al tratarse de un soporte expositivo que no estaba adaptado y deformaba la pieza [10] ${ }^{1}$. Este final para la exposición podría tratarse incluso de una instalación artística y ser estudiada desde el psicoanálisis del arte, corriente que apasionaba a David Delfín. Apreciaciones subjetivas aparte, lo cierto es que el cierre 
estaba fuera de lugar, el público no lo entendió, como ocurrió con gran parte de la exposición, y se convirtió en un área de descanso tras subir todos los escalones.

Las condiciones de la Sala Canal de Isabel II siempre son las correctas para los textiles en cuanto a luz, temperatura y humedad. Desde el punto de vista expositivo, no se trataba de una museografía novedosa pero sí efectista, de hecho, la vimos en Modus. A la manera de España (del 4 de diciembre de 2018 al 3 de marzo de 2019, Sala Canal de Isabel II, Madrid), también comisariada por Marina de Miguel, y en otras exposiciones fuera de nuestro país, como en la segunda sala de Christian Dior: Designer of Dreams (del 2 de febrero al 1 de septiembre de 2019, Victoria \& Albert Museum, Londres).

A pesar de todas las carencias señaladas, ya sea la ausencia de piezas emblemáticas, como el traje que abrió el desfile Intimidad, o el hecho de no haber tenido en cuentas las colecciones In loving memory (otoño/invierno 2003/2004), Mi manchi (primavera/verano 2004), Password (primavera/verano 2005), Diastema, Playback (primavera/verano 2010) y Cápsula (primavera/verano 2014), mientras que de otras había hasta tres looks, debemos ver esta exposición como un antecedente para los futuros homenajes que se le deben hacer a David Delfín, especialmente en Málaga, su tierra. La ciudad es todo un referente internacional en materia de museos y arte contemporáneo, por ello, no debe dejar pasar la oportunidad de crear una gran exposición que consiga descubrir al visitante, esta vez sí, la vida y obra del diseñador de Ronda.

Nota

1 Nota del Consejo de Redacción. Se ha permitido la inclusión de 10 imágenes en esta crítica como homenaje al diseñador. 